\title{
Health Equity Column: More Than A Moment: The Alliance for Black NICU Families
}

Jenné Johns, MPH

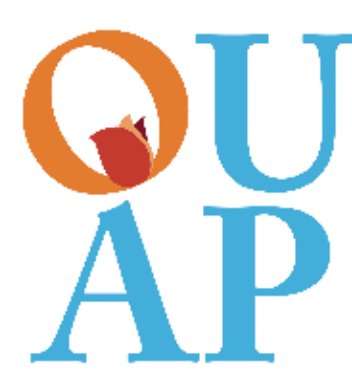

In this months' Health Equity Column, I welcome the readers of Neonatology Today to journey with me, as we take a deeper look into health and racial equity issues plaguing our society and impacting Black NICU and Preemie families. In recognition of NICU Awareness Month (a time designated to honor families experiencing a stay in the neonatal intensive care unit and the health professionals that care for them), l've interviewed Deb Discenza, Co-Founder of the Alliance for Black NICU Families for an inside look at the power of standing in solidarity and leading solutions that address health and racial equity in the NICU and beyond.

“l've interviewed Deb Discenza, Co-Founder of the Alliance for Black NICU Families for an inside look at the power of standing in solidarity and leading solutions that address health and racial equity in the NICU and beyond. "

\section{Q: What is the Alliance for Black NICU Families?}

A: These are like-minded organizations that have come together along with partner organizations, to create long-needed change in the African American community of NICU families. Too long we have seen systemic racism play its part in healthcare and the NICU is no different. Any professional that says that their NICU is not prone to systemic racism doesn't realize what implicit bias is and that it can feed into narratives behind curtains, behind closed doors. It can be as simple as not providing a family resources that would be given to anyone else in the same situation. We have to do better. We must do better.

\section{Q: Who are the members of this newly formed Alliance?}

A: We have members that span the African American leadership of NICU and preemie support groups nationwide as well as organizations that see the importance of being a part of our movement. We have also had industry representation. We are also proud to have our first international member. Racism does not know a state boundary, it does not know a country boundary either. Our members are as follows:

- $\quad$ GLO Preemies: https://www.glopreemies.com

- Connect to NICU: http://connect2nicu.com
- $\quad$ Eli Collins Foundation for Premature Babies: http://www.elibabies.org

- $\quad$ Families Blossoming: https://familiesblossoming.com

- $\quad$ Once Upon a Preemie: www.OnceUponAPreemie.com

- Pebbles of Hope: http://www.pebblesofhope.org

- $\quad$ Saul's Light: https://www.saulslight.org

- $\quad$ Mended Little Hearts: https://mendedhearts.org

- $\quad$ PreemieWorld: https://preemieworld.com

- Prolacta Bioscience: https://www.prolacta.com

- $\quad$ Sage Therapeutics: https://www.sagerx.com/

- $\quad$ Sobi Therapeutics: https://www.sobi.com/en

\section{Q: What does the formation of this Alliance mean to the neo-} natal community at this time?

A: This Alliance came about because I saw what was happening with the Black Lives Matter Movement and reached out to many of the people you see listed as members that are African American. I simply sent them messages of love and support during this turbulent time. But you, know what? That seemed hollow compared to the people risking their lives protesting in the streets around the world. I felt that as someone that is immunocompromised with an immunocompromised child (who was formerly premature), I was not helping anyone by going out and risking my health and that of my daughter. So, I thought long and hard about what I could do. And then it dawned on me that I already had a platform and that our community struggles massively under racial and health equity. Upon learning about the Once Upon A Preemie Academy, my brain started to go on overdrive. We needed to lift up the implicit bias training imperative to get things moving and to make infrastructure changes. The only way to do that is through reaching into the states' requirements for licensure. By pulling together survey data, by having partners on our partnership letter, along with our founding members, and by having petition signers included, we may see change in states. Ashley Randolph, Co- 
Founder of the Alliance for Black NICU Families and President of Glo Preemies stood in complete alignment and agreement with the importance of charge of this Alliance. As an African American led NICU support organization, Ashley knew instantly that this Alliance would move our country beyond a moment to support Black NICU Lives to a movement. Through our early outreach and awareness-raising efforts, everyone was literally onboard without much convincing. They understood the goals immediately. Same with the industry folks. They were really excited and wanted to help. And so here we are.

\section{Q: What personal and professional experiences led you and the Co-Founder to co-create the Alliance?}

A: As for me, I am not African American. I am coming from a different background as a Jewish woman that grew up with extremely dark olive-toned skin. I was picked on, I was bullied and I was treated as if I were not human. After the 2016 elections when the white supremacy movement appeared to see its moment in the sun, I had my first official hate-crime occur as an adult. While my skin tone has lightened a lot as an adult, I still look ethnic. If that is what happened to me in a single instance, I fear for the African American community that is just trying to go about their lives like every other human being on earth. The Black Lives Matters Movement is about police brutality but it shines a light on so many other inequities. Hearing Ashley and others members of the Alliance talk about this is so enlightening. Too many times and in too many ways, our country has let down the African American community and that has to stop. Ashley Randolph and I, formed this Alliance to focus on the tiniest of community members and their families- the NICU community (one in which we both experienced). We hope to plant seeds of education and advocacy and support in a very powerful way. Our first effort is health and racial equity education for the neonatal professional sector.

\section{Q: What does the Alliance want to accomplish and what is the call to action?}

A: We are hoping to garner an annual mandate for continuing education on racial and health equity for gaining and maintaining licensing for NICU and pediatric professionals. Our current goal is to get that change instituted in at least 10 states that have a significant African American populations and significant racial and ethnic disparities. We will uplift our founding member, the Once Upon A Preemie Academy as the gold standard for this continuing education.

In addition, we are asking the community at large to share this Racial and Health Equity survey with Black families that have been or are currently in the Neonatal Intensive Care Unit (NICU): https:// preemie.us/BlackNICUFamilies . For organizations interested in partnering with us we ask 1) to include their organization's name as a partner on our letterhead going out to state licensing boards and 2) Encourage Black NICU families to complete the above survey.

\section{Q: Where can we find more information about the Alliance?}

A: We have a website at https://blacknicufamilies.org. For addi- tional information on partnering with the Alliance please contact me directly at: Deb Discenza at connect@preemieworld.com

Disclosure: The author has no disclosures.

\section{NT}
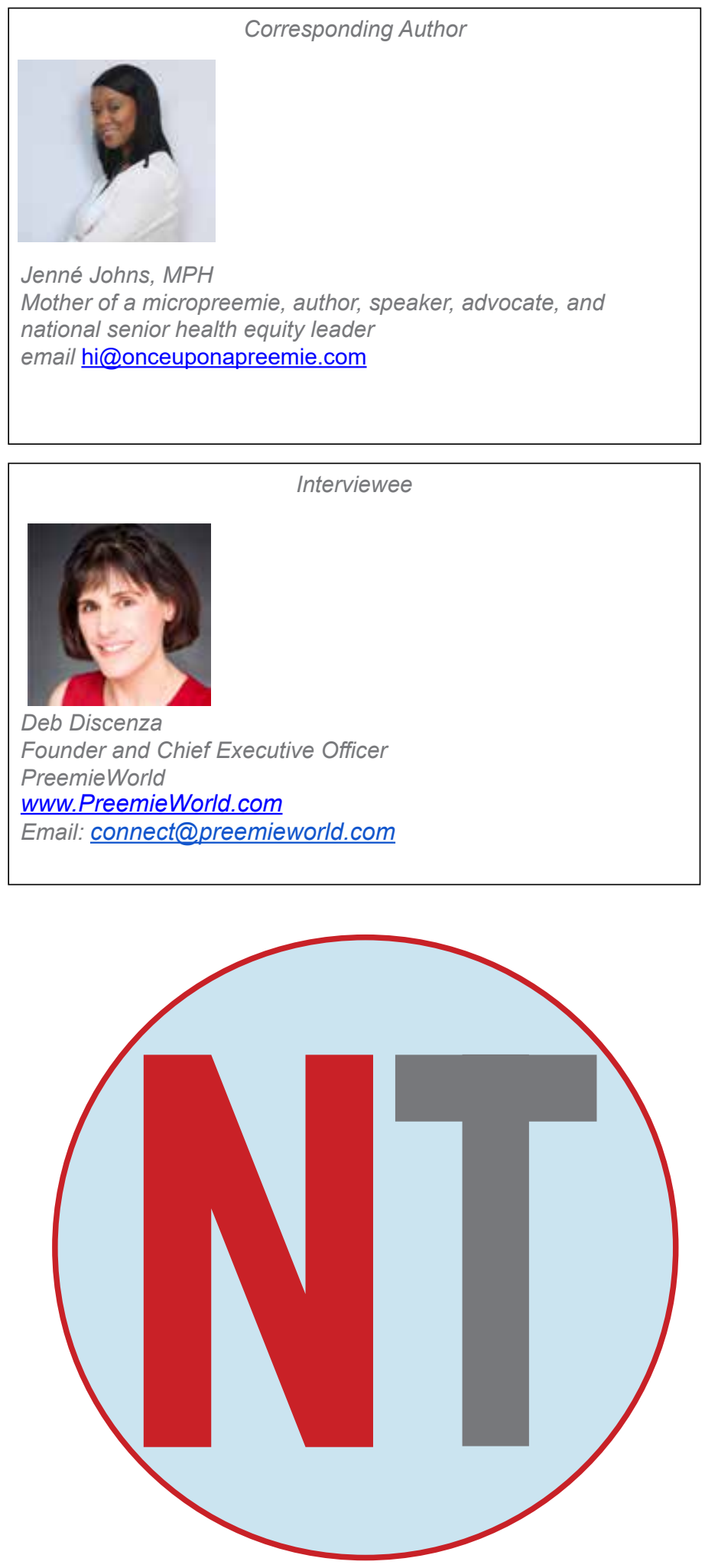